\title{
Dynamic Mechanical Analysis and Optimization of Hybrid Carbon-Epoxy Composites Wear Using Taguchi Method
}

\author{
G.S. Divyaa,b, B. Sureshaa,*, H.M. Somashekarc, I.M. Jamadara \\ a The National Institute of Engineering, Mysuru-570008, Karnataka, India, \\ ${ }^{b}$ Dayananda Sagar College of Engineering, Bengaluru-560078, Karnataka, India, \\ ${ }^{c}$ Dr. Ambedkar Institute of Technology, Bengaluru, India.
}

Keywords:

Mono and hybrid composites

Surface treatment

Dry sliding wear

Dynamic mechanical analysis

\section{* Corresponding author: \\ B. Suresha \\ E-mail: sureshab@nie.ac.in}

Received: 16 July 2020

Revised: 24 September 2020

Accepted: 22 November 2020

\begin{abstract}
A B S T R A C T
The purpose of this research work is to explore the potential of nano silicon dioxide $\left(\mathrm{nSiO}_{2}\right)$ with the carbon fiber reinforced epoxy (CF/Ep) composite for achieving better wear resistance and viscoelasticity. An effort is made to improve the material behavior by modifying epoxy with silane treated $\mathrm{nSiO}_{2}$. Ultrasonication process is used to disperse the nano particles uniformly within the matrix material. Mono CF/Ep composite and hybrid $\mathrm{nSiO}_{2}-\mathrm{CF} / \mathrm{Ep}$ composites are fabricated by vacuum bagging method. Post curing of the composites is carried out effectively. Dry sliding wear tests are conducted using Taguchi technique by considering four levels, three factors namely, filler loading $(0,0.5,1.5$, and $3 w t . \%)$, sliding velocity $(0.75,1.5,2.25$ and $3 \mathrm{~m} / \mathrm{s}$ ) and load $(15,30,45$, and $60 \mathrm{~N})$. Further from the analysis of variance, the impact of each factor and level on specific wear rate (Ks) and coefficient of friction (COF) are examined. The result revealed that the lowest Ks and COF are in $3 \mathrm{wt} . \% \mathrm{nSiO}_{2}$ filled $\mathrm{CF} / \mathrm{Ep}$ hybrid composite. The optimum control factor-level combinations identified from the experiments, for achieving lowest Ks $\left(0101 \times 10^{-13}\right.$ $\mathrm{m}^{3} / \mathrm{Nm}$ ) and COF (0.221), are $3 \mathrm{wt} . \%$ filler loading, sliding velocity of 0.75 $\mathrm{m} / \mathrm{s}$, and an applied load of $60 \mathrm{~N}$. Based on Signal to noise graph, confirmation test is conducted. Worn surface of the composites are analyzed utilizing scanning electron microscope. Damping behavior of the composites is analyzed from room temperature till $160{ }^{\circ} \mathrm{C}$. As the filler content increased, storage modulus (E') and glass transition ( $\mathrm{Tg}$ ) temperature increased. $3 \mathrm{wt} \%, \mathrm{nSiO}_{2}$ filled composite showed higher $\mathrm{E}^{\prime}$ of $18386 \mathrm{MPa}$ and $\mathrm{Tg}$ of $87.3^{\circ} \mathrm{C}$.
\end{abstract}

(C) 2021 Published by Faculty of Engineering

\section{INTRODUCTION}

Polymer composites are finding applications in automobile, aeronautics, defense, and medical sectors due to their high strength to weight ratio, good stiffness, wear and corrosion resistance, best damping behavior. Good dimensional stability, better adhesion quality, 
strong network linkage, excellent thermal stability and chemical resistance of thermoset polymers are more advantageous in manufacturing polymeric composites. Epoxy resin is a thermoset is utilized in numerous engineering materials [1,2]. Polymer based tribo-materials are replacing the heavy metal structures, housings, bed ways, sliding elements, cages of ball bearings, bearings and bushings [3].

Due to improved research and technologies, nanoparticles started emerging as the best filler materials in fiber reinforced composites over the microparticle in providing the required property benefits for the material engineers' design and products. Use of nanomaterials reduce the porosity and, improve moisture absorption resistance and high thermal stability. Nanofillers create synergistic effect among other constituents in the hybrid composites. They arrest the propagation of cracks effectively compared to microparticles. [4]. Researcher compared the effect micro and nanoparticles of $\mathrm{SiC}$ in the polymer on specific wear rate (Ks). The result indicated drastic reduction in Ks due to nanoparticles addition due to the formation of thin, homogeneous, and tenacious transfer film [5]. The trend of adding nanomaterials such as $\mathrm{Al}_{2} \mathrm{O}_{3}, \mathrm{SiO}_{2}, \mathrm{TiO}_{2}, \mathrm{ZnO}_{2}, \mathrm{ZrO}_{2}$, clay, carbon nano tubes and graphene in the thermoset polymers for obtaining good performance has been observed in recent years [6-11]. Bazrgari et al. fabricated epoxy nanocomposites by varying nano $\mathrm{Al}_{2} \mathrm{O}_{3}(30 \mathrm{~nm})$ particles from $1 \mathrm{wt} \%$ to 3 wt.\%. Wear test results revealed that 1 wt.\% filler loaded composite showed superior wear resistance [10]. Silane treated $\mathrm{nSiO}_{2}$ particles in cyanate ester resin enhanced the wear resistance and decreased the coefficient of friction (COF) due to uniform dispersion and good interface between filler and matrix [11]. Surface modified polymers will enhance the interaction and compatibility between the filler/fiber constituents in the hybrid composites [12] leading to less material loss during the wear process. Effective enhancement in the tribo properties of $\mathrm{nSiO}_{2}$ filled polymer composites is seen by surface modification of the filler [13].

Researchers started investigating the benefits in terms of density, strength, wear resistance, thermal properties and cost by combining nanoparticles in fiber reinforced polymer composites. Their research proved that addition of small quantity of nanomaterial in the fiber reinforced composites will emerge as the best material for end applications. Experiments indicated that incorporation of fillers in the glass/epoxy (G/Ep) material improve the wear resistance $[14,15]$. Nano-graphene incorporated G/Ep showed minimum COF and lower wear loss compared to mono G/Ep composites in dry sliding wear test [16]. Among G/Ep and CF/Ep composites, under constant sliding distance, lower wear loss and COF are noticed in CF/Ep composites [17]. CF/Ep composites are widely utilized for structural applications because of higher strength to weight ratio, excellent stiffness, and better corrosion and wear resistance, and good electrical properties [18]. These composites find applications in aviation, defense and sporting goods where more strength to weight ratio is preferred but as they lag in wear resistance, very minimum usage in bearing applications is noticed. To overcome this, filler addition is preferred. Inclusion of optimum amount of fillers in CF/Ep composites reduces the friction and wear loss [19] and helps in overcoming the drawbacks of mono CF/Ep composites. Incorporation of rigid ceramic $\mathrm{SiO}_{2}$ particles develops tiny and uniform transform sheet like film. This serves as promising agent in reducing wear [20]. Hybrid CF/Ep composites with nano clay and $\mathrm{ZnO}$ can be made use in manufacturing clutches, brakes, components in transmission system and also in few components of space craft [21], where lower friction and higher wear resistance is required. Feng et al. investigated dry sliding wear behavior of unfilled and nanoparticles $\left(\mathrm{TiO}_{2}\right.$, $\mathrm{SiO}_{2}$ and $\mathrm{CaCO}_{3}$ ) filled carbon fibers reinforced phenolic resin composites. They found that the lowest $\mathrm{COF}$ and best wear resistance was exhibited by $\mathrm{SiO}_{2}$ and $\mathrm{CaCO}_{3}$ filled composites [22]. Fengjun et al. studied wear behavior of nano- $\mathrm{TiO}_{2}$ particles filled $\mathrm{CF} / \mathrm{Ep}$ composites at a constant sliding velocity of $0.54 \mathrm{~m} / \mathrm{s}$ under 150 $\mathrm{N}$ and $200 \mathrm{~N}$ applied loads. The results revealed that the 3 wt.\% nano- $\mathrm{TiO}_{2}$ filled hybrid composites showed better wear resistance and least COF at higher applied load [23]. Srivastava investigated the wear behavior of multi walled carbon nano tube (MWCNT) filled CF/Ep composites under different sliding conditions and noted that application of load played a major role on wear volume loss and COF. Researcher obtained optimum wear resistance and lower COF at 2 wt.\% MWCNT filled CF/Ep 
composites [24]. Addition of the nanofiller up to 5 wt.\% reduced the Ks and COF. Further addition, increased the particle aggregation, particle-particle interface, reduced adhesion, and poor bonding between the filler and the matrix materials [25-27].

Yasmin and Daniel found increasing trend of glass transition temperatures $\left(\mathrm{T}_{\mathrm{g}}\right)$ and storage modulus (E') with the augmented graphite platelet in the epoxy composite [28]. Positive effect on dynamic mechanical properties can also be seen with fiber reinforced epoxy composites [29]. Kumaresan et al. studied the role of $\mathrm{SiC}$ in $\mathrm{CF} / \mathrm{Ep}$ composites on damping behavior. Researchers observed higher $\mathrm{T}_{\mathrm{g}}$ and improved $E^{\prime}$ in the filler incorporated composites compared to unfilled CF/Ep composites. Later, they proposed SiC incorporated composites for journal bearing applications [30]. Zhou et al. analyzed clay loading effect in epoxy and CF/Ep composites on thermal behavior. They found higher $\mathrm{E}^{\prime}$ and $\mathrm{T}_{\mathrm{g}}$ till 2 wt.\% filler loading in both type of composites, thereafter exhibited decreasing trend. Higher $\mathrm{T}_{\mathrm{g}}$ was noticed in hybrid composites [31].

From the foregoing literature discussion, it is noted that among the fiber reinforced thermoset composites, carbon fiber exhibits excellent mechanical and tribological properties. Furthermore, it is also observed that $\mathrm{nSiO}_{2}$ is the appropriate material which yields better wear resistance. No works are detected on understanding the wear and damping behavior of silane treated $\mathrm{nSiO}_{2}$ filled CF/Ep composites. Therefore, an attempt is made to investigate the synergistic behavior of carbon fiber (mat form) and different wt.\% of silane treated $\mathrm{nSiO}_{2}$ particles loading on dry sliding wear and dynamic mechanical behavior.

\section{MATERIAL AND FABRICATION}

\subsection{Materials}

Reinforcement: T300-3K 200gsm plain carbon fabric with $1.76 \mathrm{~g} \mathrm{~cm}^{-3}$ density brought from CF Composites, Delhi, India. Matrix: Araldite LY1564 epoxy resin of $1.15 \mathrm{~g} \mathrm{~cm}^{-3}$ density and Aradur 22962 hardener procured from Huntsman Ltd. Filler: $10 \mathrm{~nm}$ to $20 \mathrm{~nm} \mathrm{nSiO} 2$ particles with density $2.6 \mathrm{~g} \mathrm{~cm}^{-3}$ are procured from Sigma Aldrich Ltd, India.

\subsection{Fabrication process}

Fabrication of composites started with surface modification of the resin and filler. Epoxy resin is modified by amine containing liquid rubber hydroxyl terminated polycis-butadiene. Surface treatment of $\mathrm{SiO}_{2}$ particles is carried out using silane coupling agent (KH560) to remove hydroxyl group present on it. A solution of silane coupling agent and acetic acid was made by mixing in 1:5 weight ratios respectively. Later $\mathrm{nSiO}_{2}$ is mixed in prepared solution in $1: 1$ proportion by weight using ultrasonication process for $30 \mathrm{~min}$. After that, $\mathrm{SiO}_{2}$ particles were sieved and dried at $110^{\circ} \mathrm{C}$ for $3 \mathrm{~h}$. Figure 1 illustrates surface treatment of $\mathrm{nSiO}_{2}$ particles.

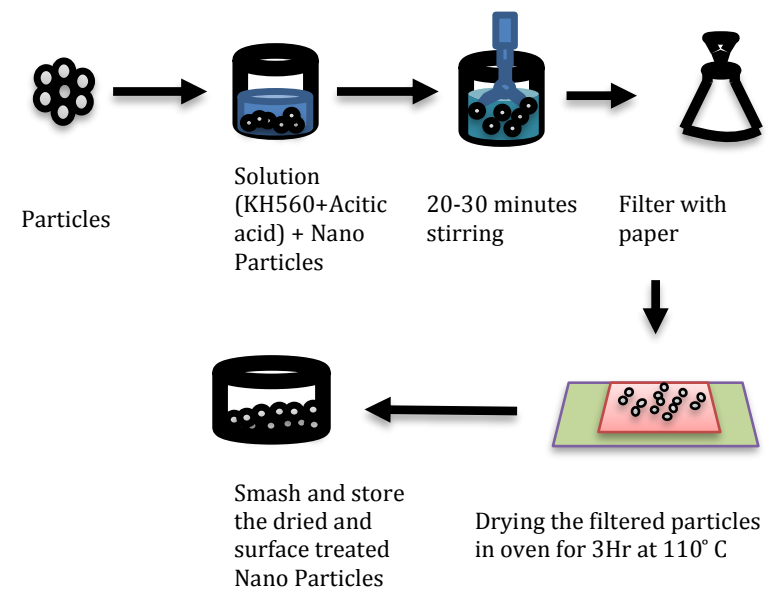

Fig. 1. Surface modification scheme for $\mathrm{nSiO}_{2}$ particles.

Final formulation based on previous literature $[32,33]$ and fabrication of mono and hybrid composites are carried listed in Table 1. Mixing ratio of epoxy and the hardener is 100:25 by weight. After fixing the reinforcement, filler and epoxy wt.\%, hand lay-up process is implemented for stacking the carbon fabric with proper epoxy coating.

Table 1. Composite codes and concentrations of various constituents of composites.

\begin{tabular}{|l|c|c|c|}
\hline \multicolumn{1}{|c|}{ Composite code } & $\begin{array}{c}\text { Fiber } \\
\text { wt.\% }\end{array}$ & $\begin{array}{c}\text { Matrix } \\
\text { wt.\% }\end{array}$ & $\begin{array}{c}\text { Filler } \\
\text { wt.\% }\end{array}$ \\
\hline $\mathrm{CF} 60 / \mathrm{Ep} 40$ & 60 & 40 & 0 \\
\hline $\mathrm{CF} 60 / \mathrm{Ep} 39.5 / \mathrm{nSiO}_{2} 0.5$ & 60 & 39.5 & 0.5 \\
\hline $\mathrm{CF} 60 / \mathrm{Ep} 38.5 / \mathrm{nSiO}_{2} 1.5$ & 60 & 38.5 & 1.5 \\
\hline $\mathrm{CF} 60 / \mathrm{Ep} 37 / \mathrm{nSiO}_{2} 3$ & 60 & 37 & 3 \\
\hline
\end{tabular}


After stacking process, the material is transferred inside the vacuum bagging system as illustrated in Fig. 2 to avoid the entrapping of air bubbles in the composite and to promote the proper curing. After vacuum bagging process, the developed laminates are post cured for $2 \mathrm{~h}$ for further improving the curing.

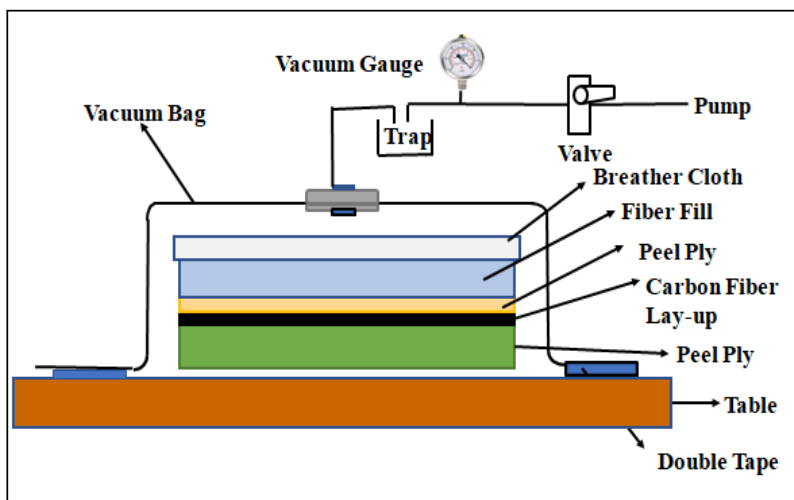

Fig. 2. Schematic diagram of vacuum bagging.

Uniform dispersion of the $\mathrm{nSiO}_{2}$ particles is achieved through ultrasonication process at room temperature for 30 minutes. After achieving uniform distribution of nanoparticles in the epoxy matrix, intended amount of hardener is added and used for further epoxy coatings on the carbon fabric.

\section{MATERIAL CHARACTERIZATION}

\subsection{Dry sliding wear test}

Dry sliding wear experiments for the fabricated CF/Ep composites with and without filler is carried out following ASTM G99 standard [34] using a Pin on disc wear test rig. Figure 3 shows the pin assembly on the rotating counterface.

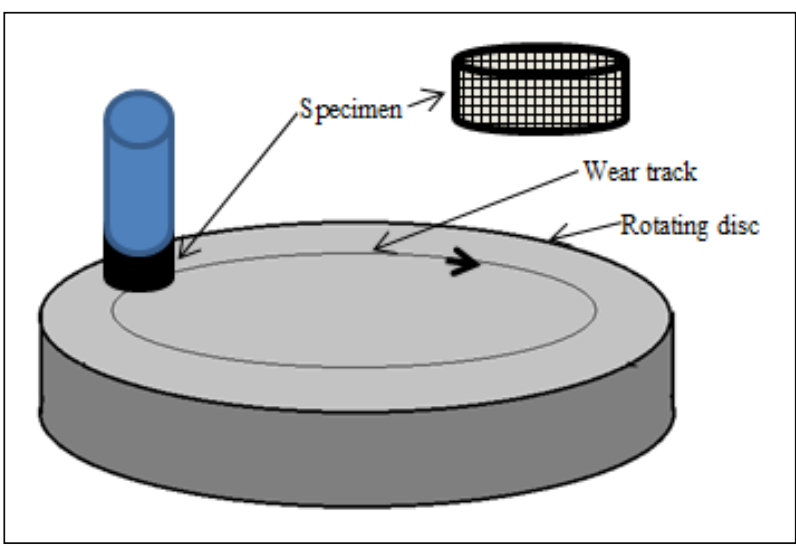

Fig. 3. Pin assembly on the rotating counterface.
Also, the machined wear test coupon and wear test coupon glued to the cylindrical pin are shown in Figs. $4 \mathrm{a}$ and $4 \mathrm{~b}$ respectively.

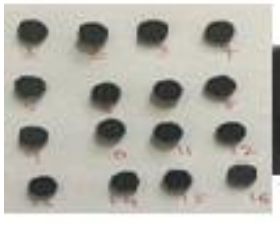

(a)

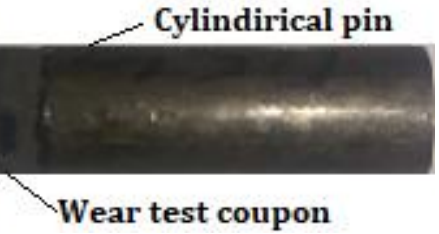

(b)
Fig. 4. (a) Wear test coupons (b) Pin assembly.

Before beginning the sliding wear test, samples are cleaned with acetone for removing the dust particles present on the sample surface. After completing the test, the debris adhered on the surface of worn samples are removed with cotton. Before and after the test weight of the wear sample is noted and the wear volume is calculated as shown in Equation (1):

$$
\mathrm{V}_{\mathrm{W}}=\frac{\mathrm{W}_{\mathrm{I}}-\mathrm{W}_{\mathrm{F}}}{\rho_{\mathrm{c}}}
$$

where, $V_{\mathrm{W}}=$ Wear volume $\left(\mathrm{m}^{3}\right), \mathrm{W}_{\mathrm{I}}=$ Initial weight of the sample $(\mathrm{g}), \mathrm{W}_{\mathrm{F}}=$ Final weight of the sample $(\mathrm{g})$, and $\rho_{\mathrm{c}}=$ Density of the composite $\left(\mathrm{g} \mathrm{m}^{-3}\right)$.

After finding the wear volume, using Equation (2), (Ks) of the composite is found.

$$
\mathrm{Ks}=\frac{\mathrm{Vw}}{\mathrm{L} \times \mathrm{D}}
$$

where, $V_{\mathrm{W}}=$ Wear volume $\left(\mathrm{m}^{3}\right), \mathrm{L}=\operatorname{Load}(\mathrm{N})$, and $\mathrm{D}=$ Sliding distance $(\mathrm{m})$.

Experiments are conducted for composites using Taguchi method to minimize the time in finding the optimum wear conditions. Factors like filler loading, sliding velocity and load are influencing more on Ks $[25,26]$ and COF at room temperature, these are taken as factors in the present research with sliding distance of $4000 \mathrm{~m}$ for all the experiment runs $[35,36]$. Control factors with four different levels as shown in the Table 2 are considered for conducting the experiments.

Table 2. Wear test factors with different levels.

\begin{tabular}{|l|l|c|c|c|c|}
\hline \multirow{2}{*}{ Control factors } & \multirow{2}{*}{ Unit } & \multicolumn{4}{|c|}{ Level } \\
\cline { 3 - 6 } & & $\mathbf{1}$ & $\mathbf{2}$ & $\mathbf{3}$ & $\mathbf{4}$ \\
\hline Filler content (A) & wt. \% & 0 & 0.5 & 1.5 & 3 \\
\hline Sliding velocity (B) & $\mathrm{m} / \mathrm{s}$ & 0.75 & 1.5 & 2.25 & 3 \\
\hline Load (C) & $\mathrm{N}$ & 15 & 30 & 45 & 60 \\
\hline
\end{tabular}


Design of experiment is well implemented through Taguchi method for conducting the experiments in an effective way by setting different testing conditions. It is a powerful statistical tool to optimize the design parameters and levels. L16 orthogonal array is used for evaluating the influence of control factors and levels on the responses like COF and Ks. Noted responses through the experiments will be converted to signal to noise ratio (SNR) to evaluate optimum combination of control factors and levels. Larger is better, nominal is better and smallest is better are available for the optimization. As the intention is find the combination which reduces the $\mathrm{Ks}$ and $\mathrm{COF}$, smallest is better category is chosen [37].

\subsection{Dynamic mechanical analysis}

Dynamic Mechanical tests are carried out according to ASTM D4065-12 standard [38] with the help of DMA Q800 V7.4 setup with $1 \mathrm{~Hz}$ frequency. Test samples with dimensions $(12.5 \times 60 \times 3 \mathrm{~mm})$ as shown in Fig. 5, are cut using abrasive water jet machine and dried in oven.

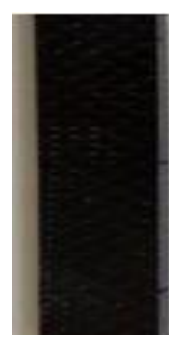

(a)

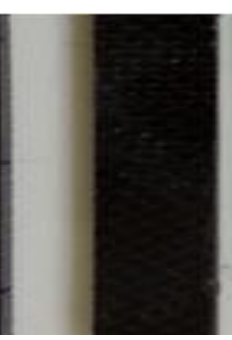

(b)

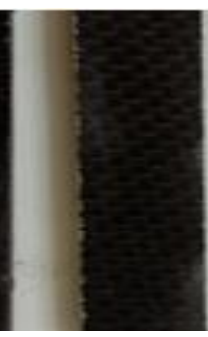

(c)

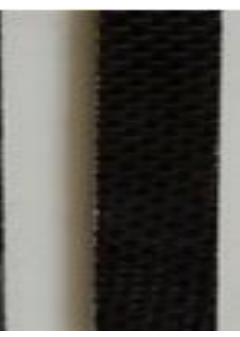

(d)
Fig. 5 Specimen for DMA testing (a) CF60/Ep40 composite, hybrid composites (b) $\mathrm{nSiO}_{2} 0.5$ (c) $\mathrm{nSiO}_{2} 1.5$ (d) $\mathrm{nSiO}_{2} 3$.

Main purpose of conducting DMA is to measure the response of the composites to an oscillatory deformation as a function of time and temperature. Measured responses are taken as storage modulus (E'), loss modulus (E") and damping factor (Tan $\delta$ ) and $\mathrm{Tg}$. Tg helps to know, where the glassy state of the material will be turning to rubbery phase.

\section{RESULTS AND DISCUSSIONS}

\subsection{Wear analysis}

Depending on the three factors namely filler loading (A), sliding velocity (B) and applied load
(C), and four levels of each factor, experiments are conducted using L16 orthogonal array. During the experiment, COF is noted and using the equations (1) and (2) Ks is calculated. Ks and COF are inserted in the derived table from Taguchi in Minitab V-19 software to get the SNR. Table 3 summarizes the obtained Ks in terms of $\left(\mathrm{x} 10^{-13}, \mathrm{~m}^{3} / \mathrm{Nm}\right)$ and COF through the experiments along with the SNR.

Table 3. Experimental results and SNR.

\begin{tabular}{|c|c|c|c|c|c|c|l|}
\hline $\begin{array}{c}\text { Expt. } \\
\text { Run }\end{array}$ & $\mathbf{A}$ & $\mathbf{B}$ & $\mathbf{C}$ & $\begin{array}{c}\text { Ks } \\
(\mathbf{1 0}-\mathbf{- 1 3}) \\
\left(\mathbf{m}^{\mathbf{3}} \mathbf{\text { Nm}} \mathbf{)}\right.\end{array}$ & $\begin{array}{c}\text { Ks- } \\
\text { SNR }\end{array}$ & COF & $\begin{array}{c}\text { COF } \\
\text {-SNR }\end{array}$ \\
\hline 1. & 0.0 & 0.75 & 15 & 0.115 & 18.7860 & 0.311 & 10.1448 \\
\hline 2. & 0.0 & 1.50 & 30 & 0.127 & 17.9239 & 0.388 & 8.2234 \\
\hline 3. & 0.0 & 2.25 & 45 & 0.138 & 17.2024 & 0.466 & 6.6323 \\
\hline 4. & 0.0 & 3.00 & 60 & 0.151 & 16.4205 & 0.491 & 6.1784 \\
\hline 5. & 0.5 & 0.75 & 30 & 0.120 & 18.4164 & 0.343 & 9.2941 \\
\hline 6. & 0.5 & 1.50 & 15 & 0.121 & 18.3443 & 0.334 & 9.5251 \\
\hline 7. & 0.5 & 2.25 & 60 & 0.137 & 17.2656 & 0.457 & 6.8017 \\
\hline 8. & 0.5 & 3.00 & 45 & 0.143 & 16.8933 & 0.451 & 6.9165 \\
\hline 9. & 1.5 & 0.75 & 45 & 0.114 & 18.8619 & 0.259 & 11.7340 \\
\hline 10. & 1.5 & 1.50 & 60 & 0.122 & 18.2728 & 0.371 & 8.6125 \\
\hline 11. & 1.5 & 2.25 & 15 & 0.117 & 18.6363 & 0.315 & 10.0338 \\
\hline 12. & 1.5 & 3.00 & 30 & 0.130 & 17.7211 & 0.350 & 9.1186 \\
\hline 13. & 3.0 & 0.75 & 60 & 0.101 & 19.9136 & 0.221 & 13.1122 \\
\hline 14. & 3.0 & 1.50 & 45 & 0.103 & 19.7264 & 0.236 & 12.5418 \\
\hline 15. & 3.0 & 2.25 & 30 & 0.106 & 19.4939 & 0.236 & 12.5418 \\
\hline 16. & 3.0 & 3.00 & 15 & 0.112 & 19.0156 & 0.273 & 11.2767 \\
\hline
\end{tabular}

Response of all controls factors and levels are measured using SNR with respect to Ks and COF are represented in Tables 4 and 5 respectively. The best wear resistance and minimum COF were at greater $\mathrm{S} / \mathrm{N}$ ratios in the response graphs (Figs. 6 and 7). In both the responses, it is clear that factor combinations of filler loading, sliding velocity and load gives minimum Ks and COF. Accordingly, minimum $\mathrm{Ks}$ and COF for the composites under study is obtained when the filler loading is at the highest level, and the sliding velocity and applied normal load are at the lowest level. Sudhir et al. also noticed minimum Ks with increase in filler loading and at lower sliding velocity/applied normal load [39].

Table 4. Response table for SNR towards Ks.

\begin{tabular}{|c|c|c|c|}
\hline Level & A & B & C \\
\hline 1 & 17.58 & 18.99 & 18.70 \\
\hline 2 & 17.73 & 18.57 & 18.39 \\
\hline 3 & 18.37 & 18.15 & 18.17 \\
\hline 4 & 19.54 & 17.51 & 17.97 \\
\hline Delta & 1.95 & 1.48 & 0.73 \\
\hline Rank & 1 & 2 & 3 \\
\hline
\end{tabular}




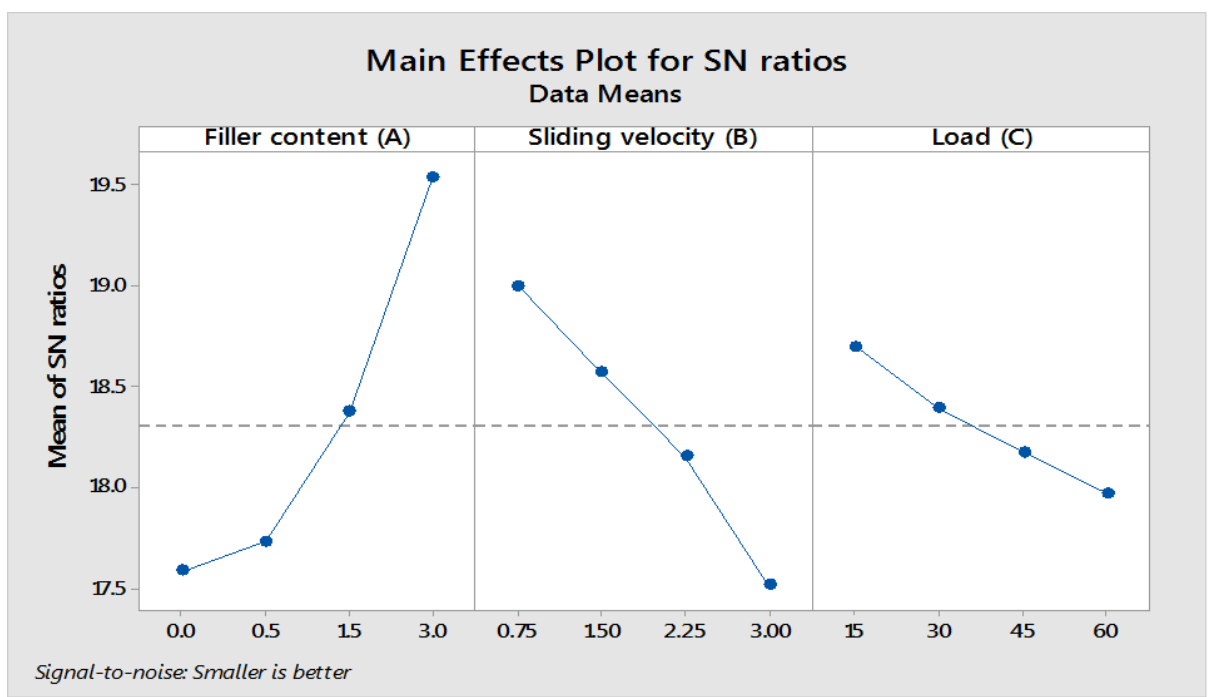

Fig. 6. Main effects plot for SNR of Ks.

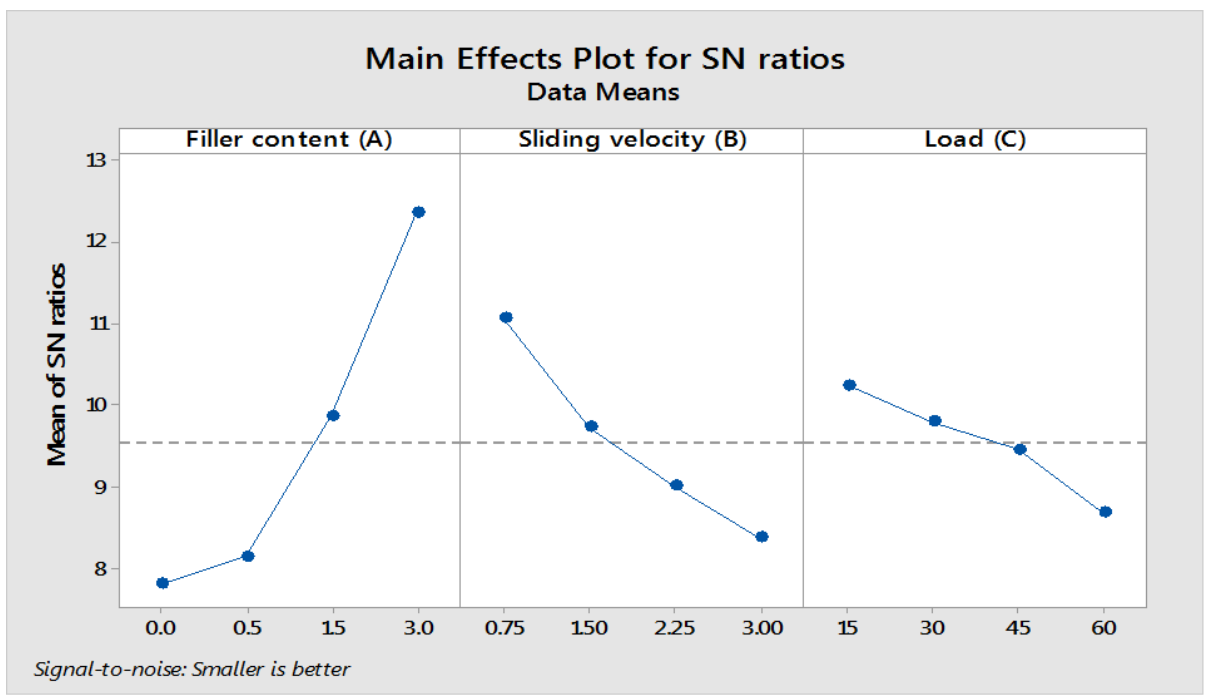

Fig. 7. Main effects plot for SNR of COF.

Table 5. Response table for SNR towards COF.

\begin{tabular}{|c|c|c|c|}
\hline Level & A & B & C \\
\hline 1 & 7.795 & 11.071 & 10.245 \\
\hline 2 & 8.134 & 9.726 & 9.794 \\
\hline 3 & 9.875 & 9.002 & 9.456 \\
\hline 4 & 12.368 & 8.373 & 8.676 \\
\hline Delta & 4.573 & 2.699 & 1.569 \\
\hline Rank & 1 & 2 & 3 \\
\hline
\end{tabular}

Main effects plot for SNR is presented in Figs. 6 and 7 for Ks and COF respectively. From the graph it is noted that higher the SNR, variance will be at lower value. The graphs also show variation in the SNR of factors with respect to different levels. It helps in further experimentation part and also in deciding the best combination yielding optimum Ks.

In case of Ks, identified optimum combination of control factor-level is $3 \mathrm{wt}$. \% filler content, 0.75 $\mathrm{m} / \mathrm{s}$ sliding velocity of and $15 \mathrm{~N}$ applied load. With the increase in filler loading, reduction in Ks is observed from the experiments. It is contrary to the trend with respect to nanoaluminium filler in CF/Ep composites. Ks noticed here at $1.50 \mathrm{~m} / \mathrm{s}$ sliding velocity and $3 \mathrm{wt} . \%$ $\mathrm{nSiO}_{2}$ filler loading is $19.85 \%$ and $25.36 \%$ less than 0.5 and 1 wt.\% Al filled composites respectively [32]. Under same sliding velocity of $1.5 \mathrm{~m} / \mathrm{s}$, sliding distance of $4000 \mathrm{~m}$, and $3 \mathrm{wt}$ \% clay and titanium oxide filled Basalt fiber reinforced epoxy composites exhibited $75 \%$ and $67.3 \%$ more Ks compared to the present work [40]. In case of COF, optimum combination is 3 wt.\% filler loading; $0.75 \mathrm{~m} / \mathrm{s}$ sliding velocity, and $15 \mathrm{~N}$ load (Fig. 7). Tables 6 and 7 are briefing about the analysis of variance (ANOVA) results on Ks and COF of the composites for the control factors in the experiments. 
Table 6. ANOVA for response of Ks.

\begin{tabular}{|c|c|c|c|c|c|c|}
\hline Source & DF & Adj SS & Adj MS & $\begin{array}{c}\text { F- } \\
\text { Value }\end{array}$ & $\begin{array}{c}\text { P- } \\
\text { Value }\end{array}$ & $\begin{array}{c}\text { P } \\
(\%)\end{array}$ \\
\hline Regression & 3 & 0.003102 & 0.001034 & 296.72 & 0.000 & - \\
\hline A & 1 & 0.001809 & 0.001809 & 519.09 & 0.000 & 57.53 \\
\hline B & 1 & 0.001000 & 0.001000 & 286.88 & 0.000 & 31.80 \\
\hline C & 1 & 0.000293 & 0.000293 & 84.19 & 0.000 & 9.31 \\
\hline Error & 12 & 0.000042 & 0.000003 & - & - & 1.33 \\
\hline Total & 15 & 0.003144 & - & - & - & - \\
\hline S= 0.0018667 R-sq= 98.67 \% R-sq(pred) $=97.64 \%$ \\
\hline
\end{tabular}

Table 7. ANOVA for response of COF.

\begin{tabular}{|c|c|c|c|c|c|c|}
\hline Source & DF & Adj SS & Adj MS & $\begin{array}{c}\text { F- } \\
\text { Value }\end{array}$ & $\begin{array}{c}\text { P- } \\
\text { Value }\end{array}$ & $\begin{array}{c}\text { P } \\
(\%)\end{array}$ \\
\hline Regression & 3 & 0.112503 & 0.037501 & 122.85 & 0.000 & - \\
\hline A & 1 & 0.073751 & 0.073751 & 241.61 & 0.000 & 63.48 \\
\hline B & 1 & 0.025848 & 0.025848 & 84.68 & 0.000 & 22.25 \\
\hline C & 1 & 0.012903 & 0.012903 & 42.27 & 0.000 & 11.10 \\
\hline Error & 12 & 0.003663 & 0.000305 & - & - & 3.15 \\
\hline Total & 15 & 0.116166 & - & - & - & - \\
\hline S= 0.0174715 R-sq= 96.85 \% R-sq(pred) $=94.27 \%$ \\
\hline
\end{tabular}

Contribution of filler loading, sliding velocity and applied normal load in case of Ks is $57.53 \%$, $31.8 \%$ and $9.31 \%$ (Table 6 ) and with respect to COF, it is $63.48 \%, 22.25 \%$ and $11.10 \%$ (Table $7)$. Influence of filler loading is more due to development of thin film on the sample surface and the steel counter face. It acts as an external factor and reduces contact between the composite and disc surfaces in turn encouraging decrement in Ks [14].

It is obvious that Ks and COF have shown decreasing trend with increase in the applied normal load and sliding velocity. Increment in the load led to thermal softening the composites and loosening the matrix which increases the Ks. Furthermore, dislodging of the matrix material uncovered the fiber as well as filler at the interface could increase the Ks. This kind of observations in Ks of filler modified fiber/epoxy composites are also found by other researchers [7-11]. It is seen that increase in the sliding velocity and load causes Ks to increase with the decrease in filler loading. Incorporation of the $\mathrm{nSiO}_{2}$ in carbon fabric reinforced epoxy decreased both Ks and COF of composites. This is on the grounds that the $\mathrm{nSiO}_{2}$ being harder and spherical improved the tribological properties of carbon fabric reinforced epoxy composites Durand et al. [41] proposed several wear mechanisms, for example, surface breaking, molecule separation, thin and thick transfer layers at the counterface and this transfer film helps in the event of polymer composites that give the effective wear protection to matrix material. Ray and Gnanamoorthy [42] clarified that three wear mechanisms, in particular: (i) matrix wear, (ii) fiber/filler wear, and (iii) fiber/matrix debonding at the interface are operative in particulate filled polymeric composites. In the current examination, it was seen that $\mathrm{nSiO}_{2}$ particles, which are hard in nature and also have spherical shape, effectively distribute uniformly and well bonded with the epoxy matrix in carbon fiber composites obviously helped in improving the wear resistance and decreased the COF.

Regression expression is formulated to know the relation among input factors and output responses using regression analysis is shown in Equations (3) and (4).

Ks $=0.10668-0.009281 \mathrm{~A}+0.009427 \mathrm{~B}+0.000255 \mathrm{C}$

$\mathrm{COF}=0.2646-0.05926 \mathrm{~A}+0.04793 \mathrm{~B}+0.001693 \mathrm{C}$

Represented mathematical expressions are verified using normal probability plots for the responses Ks and COF are obtained as shown in Figs. $8 \mathrm{a}$ and $8 \mathrm{~b}$ respectively.

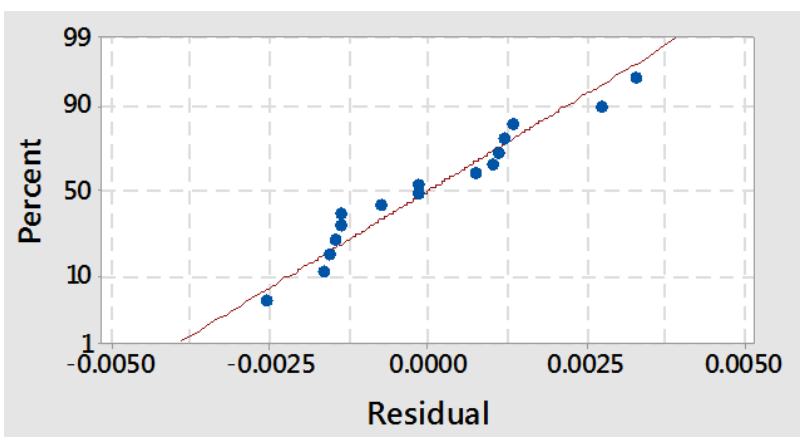

(a)

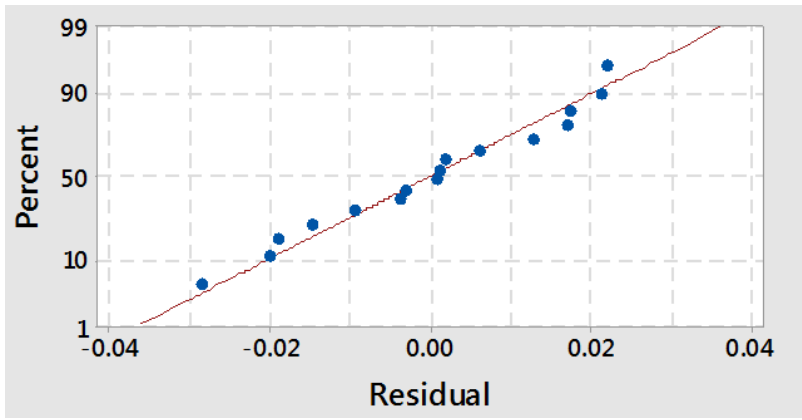

(b)

Fig. 8. Normal probability plot for (a) Ks, (b) COF.

From this, it is evident that the residuals are distributed along the line and the developed expressions are satisfactory. As per the experimental observations, due to the hybridization, the hybrid material serves the 
purpose of lubrication as well as the reinforcement effect which has improved the wear resistance and reduced the COF of CF/Ep composites [43].

To validate the conclusions drawn from Taguchi technique, confirmation test is carried out based on SNR plots under $0.75 \mathrm{~m} / \mathrm{s}$ sliding velocity and $15 \mathrm{~N}$ load based main effect plot for SNR. Result and the improvement is mentioned in Table 8. Reduction in the applied load from $60 \mathrm{~N}$ to $15 \mathrm{~N}$, has reduced SWR and COF by $22.77 \%$ and 18.09 $\%$ respectively.

Table 8. Confirmation test.

\begin{tabular}{|c|c|c|c|}
\hline & $\begin{array}{c}\text { Initial test based } \\
\text { on L16 array }\end{array}$ & $\begin{array}{c}\text { Confirmation } \\
\text { test }\end{array}$ & $\begin{array}{c}\text { Improvement } \\
\text { in the Result }\end{array}$ \\
\hline Level & A4B1C4 & A4B1C1 & \\
\hline $\begin{array}{c}\text { SWR } \\
\left(10^{-13}\right) \\
\left(\mathrm{m}^{3} / \mathrm{Nm}\right)\end{array}$ & 0.101 & 0.078 & $22.77 \%$ \\
\hline COF & 0.221 & 0.181 & $18.09 \%$ \\
\hline
\end{tabular}

Epoxy is generally considered as a brittle material, and abrasive wear is the principle wear component once they slide against a rough steel counterface. Abrasive wear is the loss of material by the entry of hard particles over a surface, during which miniature cutting, miniature crack and miniature furrowing phenomena are often viewed [44,45]. At the point when strengthened via carbon fibers and nanofillers, the wear mechanisms of hybrid composites become more complex. Figure 9a gives a typical worn surface of CF/Ep composite under $0.75 \mathrm{~m} / \mathrm{s}$ sliding velocity and $15 \mathrm{~N}$ load. It could be seen that wear of matrix, thinning of fiber, fiber fracture, and fiber/matrix debonding have happened in different regions.

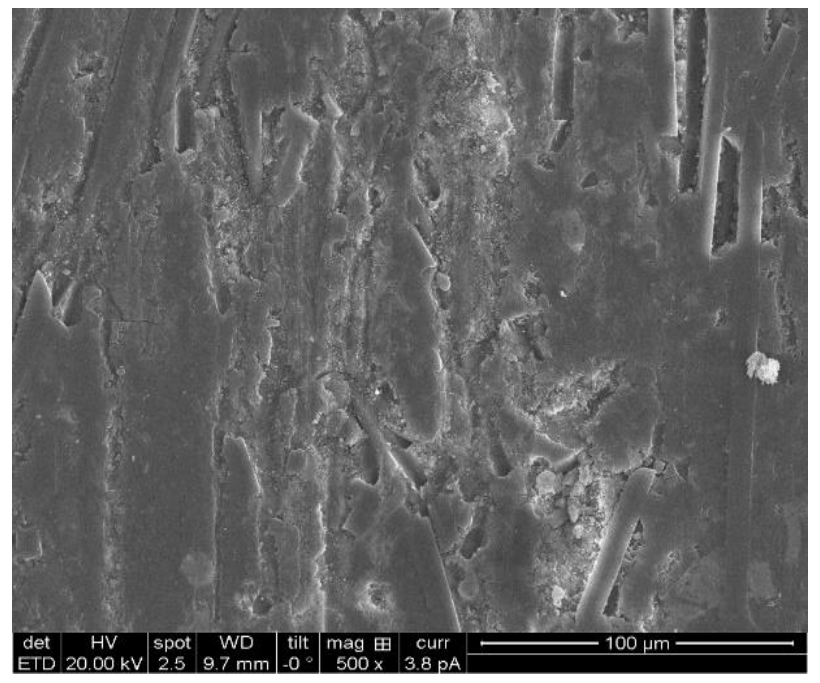

(a)

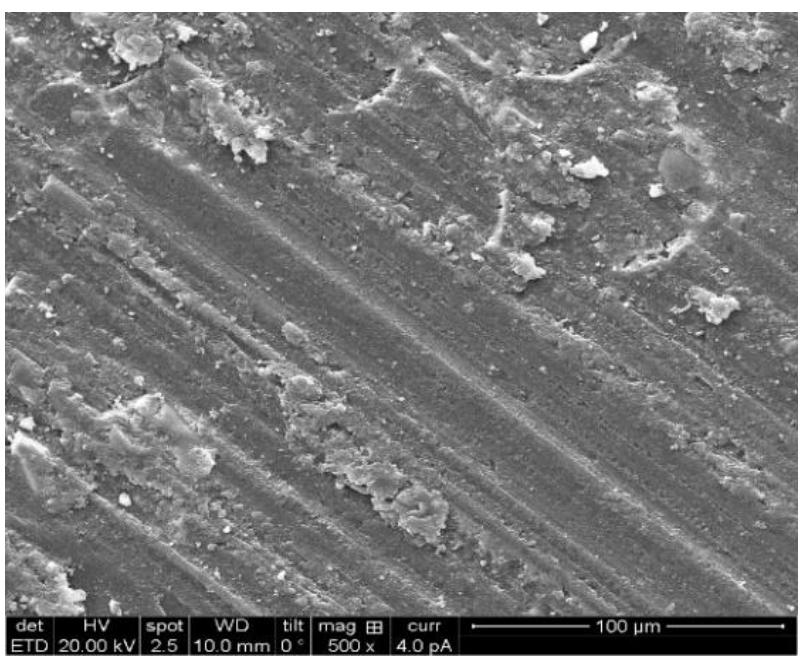

(b)

Fig. 9. SEM images of (a) CF/Ep composite, (b) $\mathrm{CF} 60 / \mathrm{Ep}^{2} 7 / \mathrm{nSiO}_{2} 3$ composite.

Figure $9 \mathrm{~b}$ highlighting on the worn surface features of $3 \mathrm{wt} . \% \mathrm{nSiO}_{2}$ filled CF/Ep composites under $0.75 \mathrm{~m} / \mathrm{s}$ sliding velocity and $15 \mathrm{~N}$ load. When $3 \mathrm{wt} . \%$ of $\mathrm{nSiO}_{2}$ particles were added to the CF/Ep composite, the worn surface of the composite showed a much smoother surface. Here, fibers are completely secured by the matrix, no fiber stripping-off and just wear of matrix can be perceived. Nano-level wear scars, lumped matrix debris, and interfacial damage between fiber and matrix can be seen on the worn surface of hybrid composite.

\subsection{Dynamic mechanical analysis}

Viscoelastic behaviour, mainly stiffness and damping are identified through their E', E" and Tan $\delta$. Influence of the nano- $\mathrm{SiO}_{2}$ particles is positive in case of E'. In hybrid composites, E" also higher compared to mono CF/Ep composites. As the filler introduced in smaller quantity, E" increased and with the more filler loading it showed decreased trend. This is the positive aspect of the hybrid materials fabricated. However, the damping factor is reduced with the introduction of filler and it is detrimental with increment of filler up to $3 \mathrm{wt} \% \mathrm{nSiO}_{2}$ loading. From the result it is also noted that, at higher wt.\% of filler addition, Tan $\delta$ started showing positive trend. CF/Ep composite with 3 wt.\% filler loading showed good E' and optimum E" and damping. Table 9 shows the noted peak E', $\mathrm{E}^{\prime \prime}$, Tan $\delta$ and $\mathrm{T}_{\mathrm{g}}$. With the addition of nano filler, significant improvement in $\mathrm{T}_{\mathrm{g}}$ also found due to influence of particles in restricting the mobility of polymer chains [46]. 
Table 9. Dynamic Mechanical Analysis results of CF/Ep and Hybrid composites.

\begin{tabular}{|c|c|c|c|c|}
\hline Composite Code & $\begin{array}{c}\text { Peak } \\
\text { Storage } \\
\text { Modulus } \\
\text { (MPa) }\end{array}$ & $\begin{array}{c}\text { Peak } \\
\text { Loss } \\
\text { Modulus } \\
\text { (MPa) }\end{array}$ & $\begin{array}{c}\text { Tg } \\
\mathbf{C C} \text { ) }\end{array}$ & $\begin{array}{c}\text { Tan } \\
\boldsymbol{\delta}\end{array}$ \\
\hline $\mathrm{CF} 60 / \mathrm{Ep} 40^{\mathrm{M}}$ & 14855.42 & 1911.12 & 85.18 & 0.594 \\
\hline $\mathrm{CF} 60 / \mathrm{Ep} 39.5 / \mathrm{nSiO}_{2} 0.5$ & 15408.82 & 5135.95 & 79.58 & 0.520 \\
\hline $\mathrm{CF} 60 / \mathrm{Ep} 38.5 / \mathrm{nSiO}_{2} 1.5$ & 16978.74 & 3912.19 & 85.22 & 0.319 \\
\hline
\end{tabular}

With the increased filler loading, E' enhanced due to enhanced glassy state [28]. This is the proof for restricted mobility of the networks in CF/Ep hybrid composites. 0.5 wt.\%, $1.5 \mathrm{wt} . \%$ and $3 \mathrm{wt} \%$ filler incorporation increased the $\mathrm{E}^{\prime}$ of CF/Ep composite by $3.72 \%, 14.29 \%$ and $23.76 \%$ respectively. Addition of filler enhanced the bond formation at room temperature as well in critical temperatures. Noted peak temperatures also more as the filler loading increased in the base material. Figure 10 shows the storage modulus of mono and hybrid CF/Ep composites.

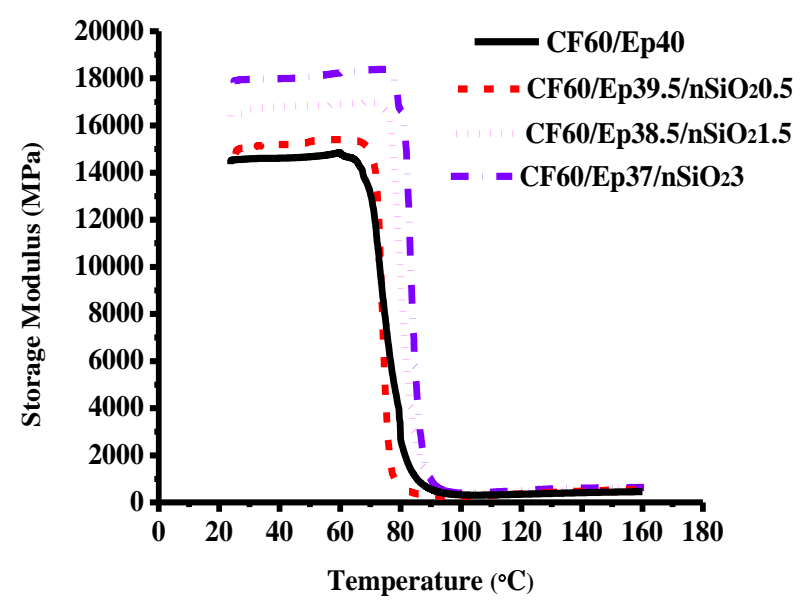

Fig. 10. Storage Modulus of unfilled and treated nano $\mathrm{SiO}_{2}$ filled CF/Ep composites.

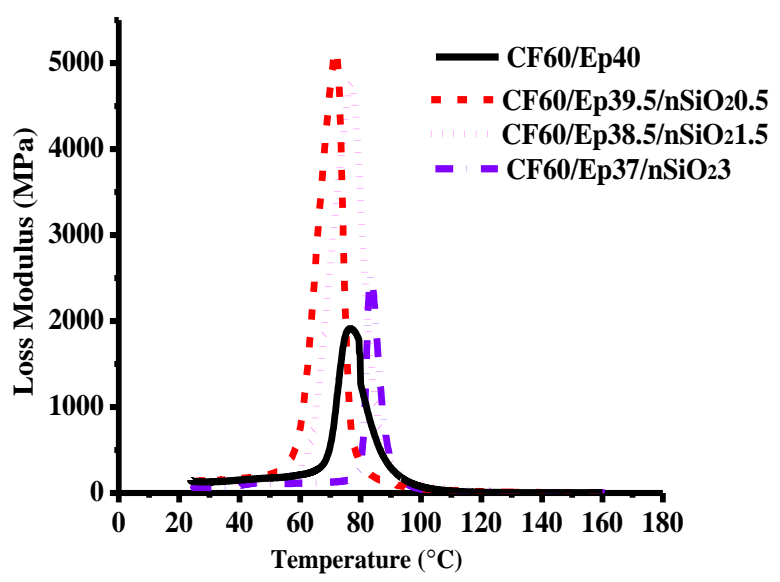

Fig. 11 Loss Modulus of unfilled and treated nano $\mathrm{SiO}_{2}$ filled CF/Ep composites.
E" of the fabricated materials is presented in Fig. 11. With the filler addition, drastic increase in the E" is noted in all hybrid composites. The positive point observed in the results is that, detrimental trend in it with the increment in filler wt.\%. With the addition of $0.5 \mathrm{wt} . \%$ filler in CF/Ep composite, E" increased by $168.74 \%$.

Further increase of filler addition to 1.5 wt.\%, decreased the E" by $23.83 \%$ compared to 0.5 wt. $\% \mathrm{SiO}_{2}$ filled composite. But again, the loss modulus is $104.71 \%$ higher than the base composite. At 3 wt.\% filler loading, loss modulus decreased compared to other two hybrid materials but it is $31.88 \%$ higher than the control mono composite.

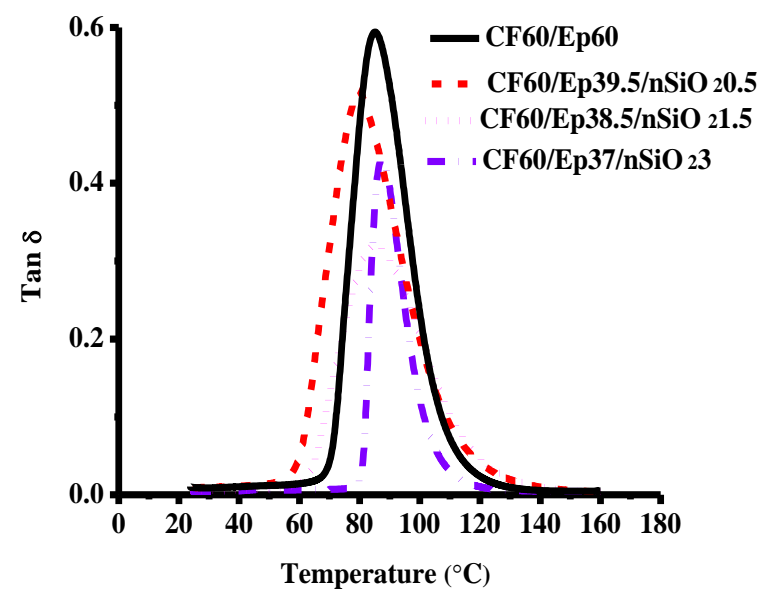

Fig. 12. Damping behaviour of unfilled and treated nano $\mathrm{SiO}_{2}$ filled CF/Ep composites.

Tan $\delta$ decreased due to presence of $\mathrm{SiO}_{2}$ particles. It is in line with Mohamad et al work on DMA of nanosilica filled hybrid composites. Addition of 0.5 wt.\% filler in CF/Basalt composites reduced Tan $\delta$ by $37.78 \%$ [47]. Fig. 12 shows the graphical presentation of damping factor for the fabricated composites. Addition of $0.5,1.5$ and 3 wt.\% nano $\mathrm{SiO}_{2}$ particles filled composites reduced the damping factor of mono composite by $12.45 \%, 46.13 \%$, and $27.6 \%$ respectively. Addition of $3 \mathrm{wt}$. \% filler increased the damping factor by $34.4 \%$ compared to 1.5 wt.\% filler loaded material. This is the proof to conclude the $3 \mathrm{wt} . \% \mathrm{nSiO}_{2}$ filled composite is the better option as this also has the higher glass transition temperature compared to all hybrid composites. The noted glass transition temperatures are between $75^{\circ} \mathrm{C}$ to $90^{\circ} \mathrm{C}$, which depicts more viscoelastic nature of the materials. These materials show both viscous and elastic behaviour [23]. 


\subsection{Correlation between sliding wear test and DMA}

From the sliding wear test and dynamic mechanical test, it is witnessed that the incorporation of $\mathrm{nSiO}_{2}$ increases $\mathrm{E}^{\prime}$ and decreases the Ks and COF. It is also observed that 3 wt.\% $\mathrm{nSiO}_{2}$ added CF/Ep composite showing the higher E', small E" and optimum Tan $\delta$ among all the fabricated materials. Higher $E^{\prime}$ implies the good measure of elasticity; the property of material to regain its shape and size without any destruction and also in this glassy region, material hardness will be more. Due to this, lower $\mathrm{Ks}$ is also noticed at 3 wt. $\% \mathrm{nSiO}_{2}$ composites. Reduced loss modulus at the higher filler incorporated composite is evident for reduced heat dissipation in the composites. This minimized the concentration of heat on the material surface in turn avoiding the material loss. $\mathrm{T}_{\mathrm{g}}$ of $3 \mathrm{wt} . \%$ particles filled CF/Ep, is high among all other materials. It is a proof for the good molecular interactions in terms of interlocking and bonding between the carbon fiber, epoxy and $\mathrm{nSiO}_{2}$ particles. Higher $\mathrm{T}_{\mathrm{g}}$ helps in arresting the polymer chain mobility at higher temperature due to strong crosslinking network. This is also a reason for the smaller Ks and COF of higher filler loaded CF/Ep composite.

\section{CONCLUSIONS}

The role of $\mathrm{nSiO}_{2}(0-3 \mathrm{wt} . \%)$ on dry sliding wear and dynamic mechanical behaviour of following Taguchi CF/Ep composites were investigated. Based on the experimental results, the conclusions can be drawn as follows:

- From Taguchi design of experiments, optimum combinations for the lowest Ks and COF are noted. In both the cases (Ks and COF) identified optimum combination of control factor-levels are $3 \mathrm{wt} . \%$ filler loading (A3), $0.75 \mathrm{~m} / \mathrm{s}$ sliding velocity (B1), and $15 \mathrm{~N}$ applied load (C1).

- From the ANOVA, it is observed that the major contribution in reducing Ks and COF is by filler loading (A3).

- Nanosilica played a key role to improve the tribo-performance of CF/Ep composites. Worn surfaces of hybrid composites showed that a nano-scale rolling effect of $\mathrm{SiO}_{2}$ particles could govern the robust improvement of the wear resistance of hybrid composites in the present investigation, which benefits to shield the worn surface of the composites from severe wear mechanisms.

- In dynamic mechanical analysis, as the wt.\% of nanofiller increased from 0.5 to $3 \mathrm{wt} \%$, higher $\mathrm{E}$ ' and ' $\mathrm{T}$ ' ' are noted. Peak E' of 18386 $\mathrm{MPa}$ and $\mathrm{T}_{\mathrm{g}}$ of $87.33^{\circ} \mathrm{C}$ is observed in $3 \mathrm{wt} . \%$ filled CF/Ep composites. Loss modulus ( $\left.\mathrm{E}^{\prime \prime}\right)$ drastically increased with the introduction of lower (0.5 wt.\%) filler loading, and on further loading of nanofiller, E" gradually decreased. Among the hybrid composites, lowest E" of $2520.52 \mathrm{MPa}$ is noticed at 3 wt. $\% \mathrm{nSiO}_{2}$ filler loading.

- Correlation between the wear and dynamic mechanical properties are discussed. Among the hybrid composites, 3 wt. $\% \mathrm{nSiO}_{2}$ filled composite showed minimum Ks, COF, E" and higher $\mathrm{E}^{\prime}$ and higher $\mathrm{T}_{\mathrm{g}}$.

\section{REFERENCES}

[1] P.S. Yadav, R. Purohit, A. Kothari, The Effect of Nano $\mathrm{SiO}_{2}$ on the Mechanical and Tribological Properties of Hybrid Polymer Matrix Composites: A Review, Advanced Materials Manufacturing \& Characterization, vol. 7, iss. 2, pp. 101-110, 2017, doi: 10.11127/ijammc2017.10.12

[2] I. Zaman, T.T. Phan, H.-C. Kuan, Q. Meng, L.T.B. La, L. Luong, O. Youssf, J. Ma, Epoxy/graphene platelets nanocomposites with two levels of interface strength, Polymer, vol. 52, iss. 7, pp. 1603-1611, 2011, doi: 10.1016/j.polymer.2011.02.003

[3] K. Friedrich, Polymer composites for tribological applications, Advanced Industrial and Engineering Polymer Research, vol. 1, iss. 1, pp. 3-39, 2018, doi: 10.1016/j.aiepr.2018.05.001

[4] O. Konovalova, J. Suchanek, F. Taticek, M. Puchnin, Tribological Analysis of the Nanomodified Industrial Polymer, Procedia Engineering, vol. 69, pp. 1481-1489, 2014, doi: 10.1016/j.proeng.2014.03.145

[5] Q.-J. Xue, Q.-H. Wang, Wear mechanisms of polyetheretherketone composites filled with various kinds of SiC. Wear, vol. 213, iss. 1-2, pp. 54-58, 1997, doi: 10.1016/S0043-1648(97)00178-6

[6] B. Wetze, F. Haupert, M.Q. Zhang, Epoxy nanocomposites with high mechanical and tribological performance, Composites Science and Technology, vol. 63, iss. 14, pp. 2055-2067, 2003, doi: 10.1016/S0266-3538(03)00115-5 
[7] N.Z. Khalil, M.F. Johanne, M. Ishak, Influence of $\mathrm{Al}_{2} \mathrm{O}_{3}$ nanoreinforcement on the adhesion and thermo mechanical properties for epoxy adhesive, Composites Part B: Engineering, vol. 172, pp. 9-15, 2019, doi: 10.1016/j.compositesb.2019.05.007

[8] F.-h. Su, Z.-z. Zhang, W.-m. Liu, Mechanical and tribological properties of carbon fabric composites filled with several nano-particulates, Wear, vol. 260, iss. 7-8, pp. 861-868, 2006, doi: 10.1016/j.wear.2005.04.015

[9] R.V. Kurahatti, A.O. Surendranathan, A.V. Ramesh Kumar, C.S. Wadageri, V. Auradi, S.A. Kori, Dry Sliding Wear behaviour of Epoxy reinforced with nano $\mathrm{ZrO}_{2}$ Particles, Procedia Materials Science, vol. 5 pp. 274-280, 2014, doi: 10.1016/j.mspro.2014.07.267

[10] D. Bazrgari, F. Moztarzadeh, A.A. Sabbagh- Alvani, M. Rasoulianboroujeni, M. Tahriri, L Tayebi, Mechanical Properties and Tribological Performance of Epoxy $/ \mathrm{Al}_{2} \mathrm{O}_{3}$ Nanocomposite, Ceramics International, vol. 44 , iss. 1 , pp. 1220 1224, 2018, doi: 10.1016/j.ceramint.2017.10.068

[11] W. Chuang, J. Geng-sheng, P. Lei, Z. Bao-lin, L. Kezhi, W. Jun-long, Influences of surface modification of nano-silica by silane coupling agents on the thermal and frictional properties of cyanate ester resin, Results in Physics, vol. 9, pp. 886-896, 2018, doi: 10.1016/j.rinp.2018.03.056

[12] S. Erden, K. Sever, Y. Seki, M. Sarikanat, Enhancement of the mechanical properties of glass/polyester composites via matrix modification glass/polyester composite siloxane matrix modification, Fiber and Polymer, vol. 11, pp. 732737, 2010, doi: 10.1007/s12221-010-0732-2

[13] M.Q. Zhang, M.Z. Rong, S.L. Yu, B. Wetzel, K. Friedrich, Effect of particle surface treatment on the tribological performance of epoxy based nanocomposites, Wear, vol. 253, iss. 9-10, pp. 10861093, 2002, doi: 10.1016/S0043-1648(02)00252-1

[14] M. Sudheer. K. Hemanth, K. Raju, T. Bhat, Enhanced Mechanical and Wear Performance of Epoxy/glass Composites with PTW/Graphite Hybrid Fillers, Procedia Materials Science, vol. 6, pp. 975-987, 2014, doi: 10.1016/j.mspro.2014.07.168

[15] B. Suresha, G. Chandramohan, J.N. Prakash, V. Balusamy, K. Sankaranarayanasamy, The Role of Fillers on Friction and Slide Wear Characteristics in Glass-Epoxy Composite Systems, Journal of Minerals \& Materials Characterization \& Engineering, vol. 5, no. 1, pp. 87-101, 2006, doi: 10.4236/jmmce.2006.51006

[16] S. Kumar, K.K. Singh, S. Kumar, Tribological Behaviour of Glass/Epoxy Laminated Composite Reinforced with Graphene and MWCNT, Materials Today: Proceedings, vol. 22, no. 4, pp. 27912797, 2020, doi: 10.1016/j.matpr.2020.03.410
[17] B. Suresha, G. Chandramohan, P. Samapthkumaran, S. Seetharamu, S. Vynatheya, Friction and Wear Characteristics of Carbonepoxy and Glass-epoxy Woven Roving Fiber Composites, Journal of Reinforced Plastics and Composites, vol. 25, iss. 7, pp. 771-782, 2006, doi: 10.1177/0731684406063540

[18] E.P. Koumoulos, A.-F. Trompeta, R.-M. Santos, M. Martins, C.M. dos Santos, V. Iglesias, R. Böhm, G. Gong, A. Chiminelli, I. Verpoest, P. Kiekens, C.A. Charitidis, Research and Development in Carbon Fibers and Advanced High-Performance Composites Supply Chain in Europe: A Roadmap for Challenges and the Industrial Uptake, Journal of Composites Science, vol. 3, iss. 3, pp. 86-93, 2019, doi: 10.3390/jcs3030086

[19] K. Kumaresan, G. Chandramohan, M. Senthilkumar, B. Suresha, S. Indran, Dry Sliding Wear Behaviour of Carbon Fabric-Reinforced Epoxy Composite with and without Silicon Carbide, Composite Interfaces, vol. 18, iss. 6, pp. 509-526, 2011, doi: 10.1163/156855411X610241

[20] M.Q. Zhang, M.Z. Rong, S.L. Yu, B. Wetzel, K. Friedrich, Improvement of tribological performance of epoxy by the addition of irradiation grafted nanoinorganic particles, Macromolecular Materials and Engineering, vol. 287, iss. 2, pp. 111-115, 2002, doi: 10.1002/1439-2054(20020201)287:2<111::AIDMAME111>3.0.CO;2-I

[21] V.K. Tripathi, S. Ambekar, Optimization and Analysis of Wear Rate of CFRPNanoZno/Nanoclay Hybrid Composites Using RSM, Journal of Bio- and Tribo-Corrosion, vol. 5, no. 96, 2019, doi: 10.1007/s40735-019-0284-y

[22] F.-h. Su, Z.-z. Zhang, W.-m. Liu, Mechanical and tribological properties of carbon fabric composites filled with several nano-particulates, Wear, vol. 260, iss. 7-8, pp. 861-868, 2006, doi: 10.1016/j.wear.2005.04.015

[23] F. Wei, B. Pan, J. Lopez, The tribological properties study of carbon fabric/epoxy composites reinforced by nano-TiO 2 and MWNTs, Open Physics, vol. 16, iss. 1, pp. 1127-1138, 2018, doi: $10.1515 /$ phys-2018-0133

[24] V.K. Srivastava, Effect of CNTs on the Wear and Friction Performance of Carbon Fibre Woven Fabric Reinforced Epoxy Resin Composites, International Journal of Composite Materials, vol. 6, no. 4, 2016, doi: 10.5923/j.cmaterials.20160604.02

[25] M.S. Senthil Kumar, N.M. Sundara Raju, P.S. Sampath, U. Vivek, Tribological Analysis of Nano Clay/ Epoxy/ Glass Fiber by using Taguchi's Technique, Materials \& Design, vol. 70, pp. 1-9, 2015, doi: 10.1016/j.matdes.2014.12.033

[26] Rashmi, N.M. Renukappa, B. Suresha, R.M. Devarajaiah, K.N. Shivakumar, Dry sliding wear 
behaviour of organo-modified montmorillonite filled epoxy nanocomposites using Taguchi's techniques, Materials \& Design, vol. 32, iss. 8-9, pp. 4528-4536, 2011, doi: 10.1016/j.matdes.2011.03.028

[27] B. Suresha, K. Adappa, N.K. Subramani, Mechanical and Tribological behaviours of Epoxy hybrid Composites Reinforced by Carbon Fibers and Silicon carbide Whiskers, MaterialsToday: Proceedings, vol. 5, iss. 8, pp. 16658-16668, 2018, doi: 10.1016/j.matpr.2018.06.027

[28] A. Yasmin, I.M. Daniel, Mechanical and thermal properties of graphite platelet/epoxy composites, Polymer, vol. 45, iss. 24, pp. 8211-8219, 2004, doi: 10.1016/j.polymer.2004.09.054

[29] K.E. Atkinson, C. Jones, A Study of the Interphase Region in Carbon Fibre/Epoxy Composites using Dynamic Mechanical Thermal Analysis, The Journal of Adhesion, vol. 56, iss. 1-4, pp. 247260, 1996, doi: 10.1080/00218469608010511

[30] K. Kumaresan, G. Chandramohan, M. Senthilkumar, B. Suresha B, Dynamic mechanical analysis and three body wear of carbon epoxy composite filled with SiC particles, Journal of Reinforced Plastics and Composites, vol. 31, iss. 21, pp. 1435-1448, 2012, doi: $10.1177 / 0731684412459250$

[31] Y. Zhou, M. Hosur, S. Jeelani, P.K. Mallick, Fabrication and characterization of carbon fiber reinforced clay/epoxy composite, Journal of Materials Science, vol. 47, pp. 5002-5012, 2012, doi: $10.1007 / s 10853-012-6376-4$

[32] G.S. Divya, B. Suresha, Role of Metallic Nanofillers on Mechanical and Tribological Behaviour of Carbon Fabric Reinforced Epoxy Composites, Materials Sciences and Applications, vol. 9, no. 9, pp. 740-750, 2018, doi: 10.4236/msa.2018.99054

[33] B.N. Ramesh, B. Suresha, D. Chandramohan, D. Anjaiah, Three-Body Abrasive Wear Behaviour of Microfiller-Filled Carbon-Epoxy Composites: A Factorial Design Approach, Composite Interfaces vol. 18, iss. 9, pp. 783-800, 2011, doi: 10.1163/156855412X629619

[34] ASTM G99-17, Standard Test Method for Wear Testing with a Pin-on-Disk Apparatus, ASTM International, West Conshohocken, PA, 2017.

[35] J. Sudeepan, K. Kumar, T.K. Barman, P. Sahoo, Study of friction and wear properties of ABS/Kaolin Polymer composites using grey relational technique, Procedia Technology vol. 14, pp. 196-203, 2014, doi: 10.1016/j.protcy.2014.08.026

[36] R.V. Kurahatti, A.O. Surendranathan, A.V. Ramesh Kumar, C.S. Wadageri, V. Auradi, S.A. Kori, Dry Sliding Wear behaviour of Epoxy reinforced with nano $\mathrm{ZrO}_{2}$ Particles, Procedia Materials Science, vol. 5, pp. 274-280, 2014, doi: 10.1016/j.mspro.2014.07.267
[37] J. Sudeepan, K. Kumar, T.K. Barman, P. Sahoo, Study of Friction and Wear of ABS/Zno Polymer Composite Using Taguchi Technique, Procedia Materials Science, vol. 6, pp. 391-400, 2014, doi: 10.1016/j.mspro.2014.07.050

[38] ASTM D4065-12, Standard Practice for Plastics: Dynamic Mechanical Properties: Determination and Report of Procedures, 2012.

[39] M. Sudheer, R. Prabhu, K. Raju, T. Bhat, Optimization of Dry Sliding Wear Performance of Ceramic Whisker Filled Epoxy Composites Using Taguchi Approach, Advances in Tribology, vol. 2012, 2012, doi: 10.1155/2012/431903

[40] C.R. Mahesha, Shivarudraiah, N. Mohana, M. Rajesh, Role of Nanofillers on Mechanical and Dry sliding Wear Behavior of Basalt- Epoxy Nanocomposites, MaterialsToday: Proceedings, vol. 4, iss. 8, pp. 8192-8199, 2017, doi: 10.1016/j.matpr.2017.07.161

[41] J.M. Durand, M. Vardavoulias, M. Jeandin, Role of Reinforcing Ceramic particles in the Wear behaviour of Polymer based model Composites, Wear, vol. 181-183, no. 2, pp. 833-839, 1995, doi: 10.1016/0043-1648(95)90203-1

[42] D. Ray, R. Gnanamoorthy, Friction and Wear behaviour of Vinylester resin matrix Composites filled with Fly ash particles, Journal of Reinforced Plastics and Composites, vol. 26, iss. 1, pp. 5-13, 2007, doi: 10.1177/0731684407069945

[43] Y. He, D. Wu, M. Zhou, H. Liu, L. Zhang, Q. Chen, B. Yao, D. Yao, D. Jiang, C. Liu, Z. Guo, Effect of MoO3 /carbon nanotubes on friction and wear performance of glass fabric-reinforced epoxy composites under dry sliding, Applied Surface Science, vol. 506, 2020, doi: 10.1016/j.apsusc.2019.144946

[44] E. Kazemi-Khasragh, F. Bahari-Sambran, C. Platzer, R. Eslami-Farsani, The synergistic effect of graphene nanoplatelets-montmorillonite hybrid system on tribological behavior of epoxy-based nanocomposites, Tribology International, vol. 151, 2020, doi: 10.1016/j.triboint.2020.106472

[45] Stachowiak, G. Batchelor, A.W, Engineering tribology. Butterworth-Heinemann, 2013.

[46] 0. Konovalova, J. Suchanek, F. Taticek, M. Puchnin, Tribological Analysis of the Nanomodified Industrial Polymer, Procedia Engineering vol. 69, pp. 1481-1489, 2014, doi: 10.1016/j.proeng.2014.03.145

[47] M. Alsaadi, M. Bulut, A. Erklig, Nano-silica inclusion effects on mechanical and dynamic behavior of fiber reinforced carbon/Kevlar with epoxy resin hybrid composites, Composites Part B: Engineering, vol. 152, pp. 169-179, 2018, doi: 10.1016/j.compositesb.2018.07.015 